\title{
A Mini Review on Discovery and Synthesis of Remdesivir as an Effective and Promising Drug against COVID-19
}

\author{
E. Zarenezhad ${ }^{a, 1}$, S. Behrouz ${ }^{b}$, M. Farjam ${ }^{a, c}$, and M. N. Soltani Rad ${ }^{b}$ \\ ${ }^{a}$ Noncommunicable Diseases Research Center, Fasa University of Medical Sciences, Fasa, Iran \\ ${ }^{b}$ Medicinal Chemistry Research Laboratory, Department of Chemistry Shiraz University of Technology, Shiraz, 71555-313 Iran \\ ${ }^{c}$ Department of Medical Pharmacology, School of Medicine, Fasa University of Medical Sciences, Fasa, Iran
}

Received November 25, 2020; revised December 8, 2020; accepted December 12, 2020

\begin{abstract}
The severe acute respiratory syndrome coronavirus-2 (SARS-CoV-2) as a new human coronavirus has begun spreading over Wuhan City/China in December 2019, and then spread rapidly worldwide, causing pneumonia called COVID-19. Up to now, the scientists have extensively attempted to find effective vaccines and drugs for treatment of coronavirus infections. To this end, various pharmaceutical agents are undergoing the clinical studies to assess their potency and efficacy against COVID-19. Based on the new findings, the U.S. food and drug administration (FDA) has issued an emergency use authorization for remdesivir as an effective anti-viral for remedying the hospitalized COVID-19 patients. Recently, the European medicines agency has authorized the use of remdesivir for the treatment of COVID-19. Remdesivir as a nucleotide prodrug exhibits broad-spectrum antiviral activities against RNA viruses. In this short review, we have rendered a brief overview of discovery and synthesis for remdesivir.
\end{abstract}

Keywords: remdesivir, coronavirus, COVID-19, synthesis, SARS-CoV-2

DOI: $10.1134 / \mathrm{S} 1068162021030183$

\section{INTRODUCTION}

Coronaviruses (CoVs) belong to a family of enveloped viruses with single strand of positive sense RNA that infects humans and various animals. The corona virus has four genera: $\alpha, \beta, \gamma$ and $\delta$ as well as several subgenera [1]. The severe acute respiratory syndrome coronavirus 2 (SARS CoV-2) is known as a $\beta$-corona-

\footnotetext{
Abbreviations: $\mathrm{BCl}_{3}$, boron trichloride; $n$-BuLi, $n$-Butyl lithium; CDC, centers for disease control and prevention; COVID-19, corona virus disease 2019; DCM, dichloromethane; DENV-2, Dengue-2 virus; DNA, deoxyribonucleic acid; DYKAT, dynamic kinetic asymmetric transformation; EBOV, Ebola virus; EMA, European medicines agency; $\mathrm{HCl}$, hydrochloric acid; HCV, Hepatitis C virus; HMVEC, Hela and Human umbilical vein endothelial cells; HPLC, high performance liquid chromatography; $\mathrm{H}_{2} \mathrm{SO}_{4}$, sulfuric acid; i- $\mathrm{PrMgCl}$. $\mathrm{LiCl}$, isopropyl magnesium chlorid lithium chlorid; i-PrOAC, isopropyl acetate; MERS, Middle east respiratory syndrome; $\mathrm{MgCl}_{2}$, magnesium chloride; MTBE, methyl tert-butyl ether; $\mathrm{NdCl}_{3}$, neodymium trichloride; $\mathrm{PhMgCl}$, Phenyl magnesium chloride; $\mathrm{RCV}$, rat corona virus; RNA, ribonucleic acid; $\mathrm{S}_{\mathrm{N}} 2$, substitution nucleophilic biomolecular reaction; SARS-CoV, severe acute respiratory syndrome coronavirus; SARS-CoV-2, severe acute respiratory syndrome coronavirus 2 ; TFA, tri fluoro acetic acid; $\mathrm{TfOH}$, tri fluoromethanesulfonic acid; THF, tetrahydrofuran; TMS, trimethylsilyl chloride; TMSCN, trimethylsilyl cyanide; TMSOTf, trimethylsilyl trifluoromethanesulfonate; USAMRIID, U.S. army medical research institute of infectious diseases; U.S.FDA, U.S. food and drug administration; WHO, World Health Organization; YFV, yellow fever virus.

${ }^{1}$ Corresponding author: e-mail: El.zarenezhad@gmail.com, El.Zarenezhad@fums.ac.ir.
}

virus [2] which causes the disease COVID-19 [3]. In 1960 , it was discovered that corona virus causes the intestinal infections in several animals and humans. They were also supposed to be the responsible for mild illness such as the common cold [4]. Unfortunately, in 2003 this virus has mutated which caused the SARS pandemic and middle east respiratory syndrome (MERS) pandemic in 2012 which resulted in the mortality rates more than 10 and $35 \%$, respectively [5]. In December 2019, world health organization [6] reported the new coronavirus SARS $\mathrm{CoV}-2$ which resulted in an outbreak of pathogenic viral pneumonia in Wuhan, Hubei Province, China [6]. Subsequently, on March 11, 2020, WHO declared the SARS CoV-2 as a global pandemic [6].

Until now, there is not clinically proven therapeutics for COVID-19 as a new pathogenic disease. However, there are few clinical trials on potential antiviral therapies [7]. Remdesivir (Veklury, CAS no. 180924937-3) as one of the first and effective clinical candidates has received considerable attention in recent months. In 2015, this antiviral drug was reported with effective results against Ebola virus (EBOV) [8]. The U.S. food and drug administration (FDA) has issued an emergency use authorization for using remdesivir as the treatment of hospitalized COVID-19 patients. Recently, European medicines agency has authorized 


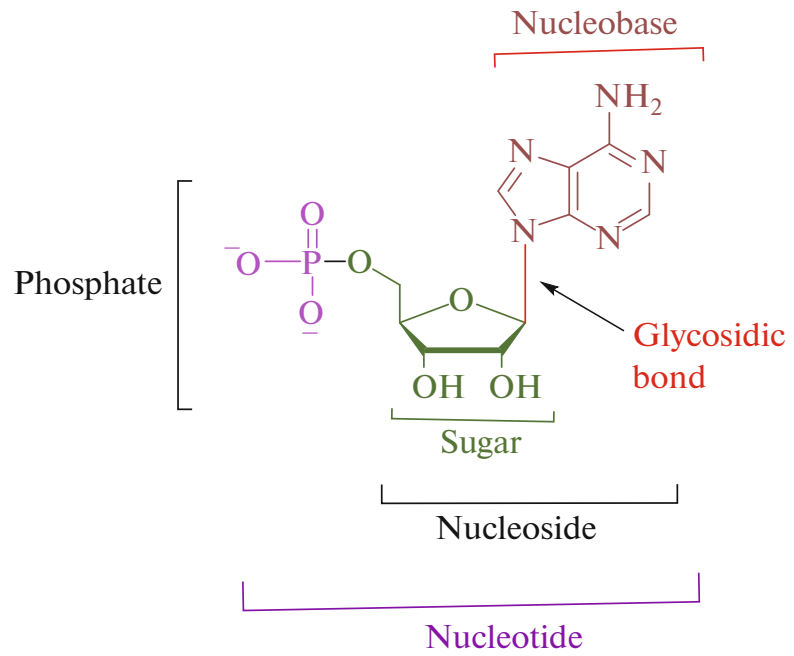

Fig. 1. Structure of nucleoside and nucleotide analogues.

the use of remdesivir for the treatment of COVID-19 [9]. Remdesivir inhibits viral RNA synthesis and shows the activity in animal models and cell culture against SARS-CoV, MERS-CoV, and SARS-CoV-2 [10].

\section{RESULTS AND DISCUSSION}

\section{Nucleosides and Nucleotides Structure}

Primarily, Levene and Jacobs used the term of "nucleoside" in 1909 [11]. Nucleosides have similar structures to nucleotides. In general, nucleotide con- tains a nucleobase, sugar, and at least one phosphate (or phosphate-like) group while nucleoside merely contains nucleobase and sugar moieties (Fig. 1).

\section{Natural Nucleosides}

Natural nucleosides are those obtained from hydrolysis of RNA and DNA in the living cells as well as biochemical events that metabolize the classic nucleosides into their corresponding derivatives. This modification or changes in structure can be achieved on either nucleobases or sugar moiety distinctly or simultaneously. As an instance, the alteration in adenine residue of adenosine resulted in inosine by a metabolic action of adenosine deaminase in living cell [12]. The most abundant classic nucleosides in living organisms are represented in Fig. 2.

\section{Modification in Nucleosides Structure}

The wonderful therapeutic behavior of classic nucleosides from many aspects of drug discovery as well as their wide biochemical studies have encouraged many medicinal chemists to synthesis a large number of classic nucleoside derivatives. The modifications and/or alterations on structure of nucleosides can be conducted either partially or fundamentally. In partial modifications, the altered structure has a remarkable resemblance to its parent classic nucleosides whereas in the fundamental modifications; the structure has a few similarities. Considering the general structure of classic nucleosides shown in Fig. 3,

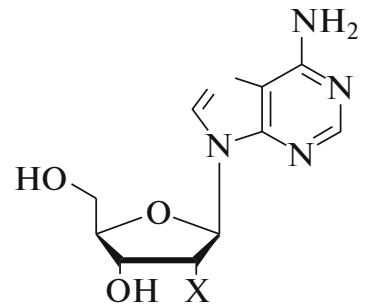

$\mathrm{X}=\mathrm{OH}$ (Adenosine)

$\mathrm{X}=\mathrm{H}$ (Deoxyadenosine)<smiles>[X]C1OC(O)C(O)C1n1ccc(=O)[nH]c1=O</smiles>

$\mathrm{X}=\mathrm{OH}($ Uridine $)$

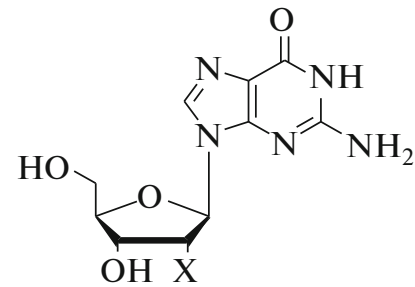

$\mathrm{X}=\mathrm{OH}$ (Guanosine)

$\mathrm{X}=\mathrm{H}$ (Deoxyguanosine)

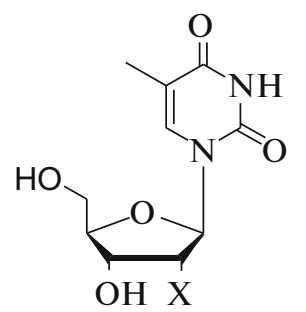

$\mathrm{X}=\mathrm{H}$ (Thymidine)

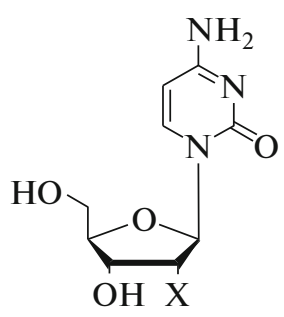

$\mathrm{X}=\mathrm{OH}$ (Cytidine)

$\mathrm{X}=\mathrm{H}$ (Deoxycytidine)

Fig. 2. Natural nucleosides.

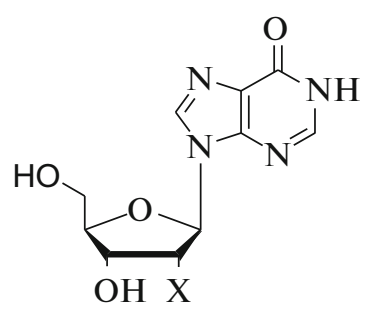

$\mathrm{X}=\mathrm{OH}$ (Inosine) 
the modification in structure can be categorized in; (I) nucleobases; (II) side chains and (III) sugar moiety [13-16].

\section{Sugar Modifications}

The broad range of biological activity of sugarmodified nucleosides has brought them to main synthetic targets and useful candidates to develop the modified drug therapies to treat the human diseases. These nucleoside derivatives were known to be as interesting and useful agents in cancer and viral chemotherapy [17]. The SAR analysis has well indicated that the addition of the 1'-methyl group not only causes the instability of the glycosidic bond but also in turn leads to the lack of activity displayed by 1 '-analogues of nucleosides [18, 19]. Generally, the glycosidic linkage is stable under physiological conditions; however, several factors such as $\mathrm{pH}, 1^{\prime}$-substituents and type of nucleobase, can extensively affect this bond [19-22]. Additionally, replacing the substituent from hydrogen to any other groups at the 1' position could have an intense effect on glycosidic bond cleavage either through electronic or steric effects [20, 23, 24]. Researchers reported that by replacing $(\mathrm{O}-\mathrm{C}-\mathrm{N})$ glycosidic bond with $(\mathrm{O}-\mathrm{C}-\mathrm{C})$ bond which is found in C-nucleosides then, one would be able to add 1'-substituents without compromising the integrity of the glycosidic bond $[20,25,26]$. The SAR study on several 1 '-substituted analogues demonstrated that the 1 '-cyano analogue shows a wide range of antiviral activity against plenty of viruses such as hepatitis $\mathrm{C}$ virus (HCV), influenza $A$, par influenza, yellow fever virus (YFV), dengue-2 virus (DENV-2), SARS-CoV, with the greatest antiviral activity against Ebola virus (EBOV) [19, 27]. Since 1'-cyano analogue exhibited wide spectrum of antiviral activity, scientists at Gilead carried out a computational docking study with the triphosphate analogue of the 1'-cyano analogue of nucleosides and diverse RNA virus polymerases. They have also determined that the 1 '-cyano group occupies a major pocket present only in the viral polymerase binding site, which causes the increased selectivity of the 1'-cyano analogues for viral polymerases over human polymerases $[27,28]$.

\section{Development and Synthesis of Remdesivir}

A successful collaboration between Gilead, the U.S. centers for disease control and prevention (CDC) and the U.S. army medical research institute of infectious diseases (USAMRIID) resulted in formulation of remdesivir (Veklury, GS-5734). The scientists intended to find therapeutic agents for treating disease caused by RNA viruses such as EBOV and the coronaviridae family viruses like SARS and MERS. At the

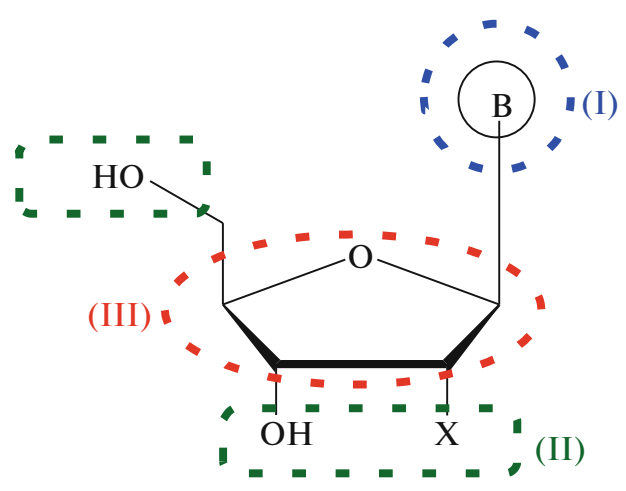

Fig. 3. General changes in structure of classic nucleosides. Modification in structure can be categorized in (I) nucleobases (blue); (II) side chains (green) and (III) sugar moiety (red).

beginning of the exploration, almost a library of 1000 various nucleoside derivatives was evaluated based on the previous information on potent antiviral compounds that targeting RNA viruses. Since nucleosides are known as cell-permeable compounds, then the modified nucleosides by group such as monophosphate, ester, and phosphoramidate prodrugs involve as a considerable part of the library [29, 30]. Researcher at Gilead Sciences found that 1'-CN modified adenosine $C$-nucleoside exhibits potent activity against EBOV in Hela and Human umbilical vein endothelial cells (HMVEC) [27, 31]. This effective compound was named as remdesivir (GS-5734). Remdesivir is one of the clinical candidates for EBOV that has received particular attention as a drug candidate against novel 2019 corona virus $[8,32]$. According to the obtained results, the parent nucleoside 1 and its potent phosphoramidate prodrug diastereoisomer 2 (GS-5734) were selected for further development (Fig. 4). The prodrug diastereoisomer 2 has effective in vitro activity against human and zoonotic coronaviruses like RCV (rat coronavirus), $\mathrm{HCV}, \mathrm{MERS}-\mathrm{CoV}$ and SARS-CoV. Compound 1 is also shown potent anti-EBOV activity. This broad-spectrum antiviral activity of 2 (remdesivir) has been led to its investigation against the 2020 pandemic Covid-19 caused by SARS-CoV-2.

Remdesivir as an RNA polymerase inhibitor can be converted into its triphosphate metabolite $\mathbf{3}$ in human cells which is taken up in place of adenosine triphosphate by the viral RNA polymerase, thereby crippling the virus replication (Fig. 5) [1].

The researchers at Gilead [27] synthesized compound 1, starting from tribenzyl protected lactol 4 followed by oxidation to its corresponding lactone $\mathbf{5}$ (Scheme 1). 


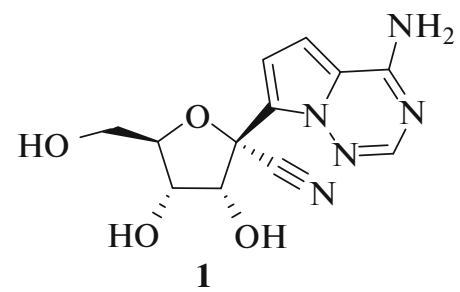

GS-441524

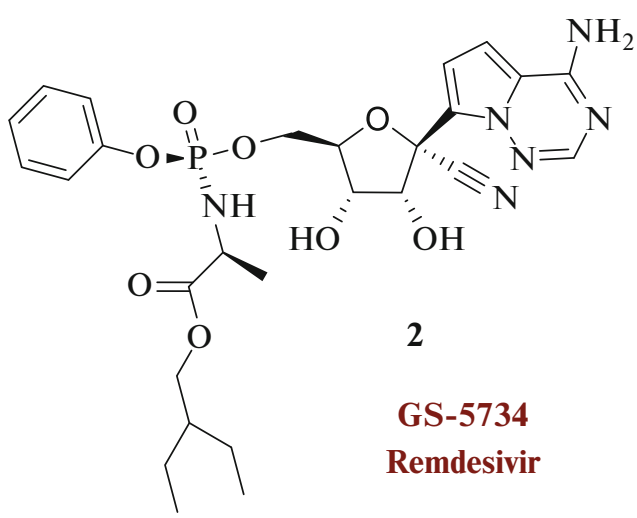

Fig. 4. Structures of compounds 1 and remdesivir.

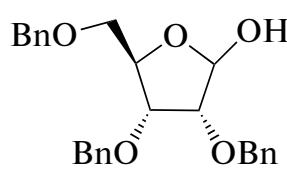

4

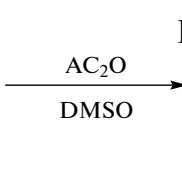

(1)

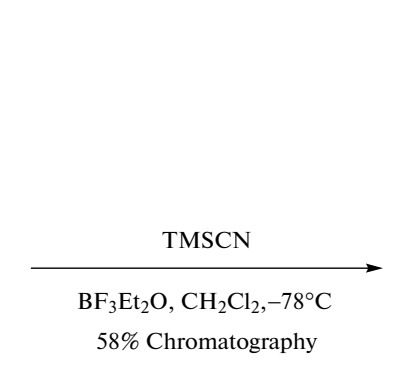

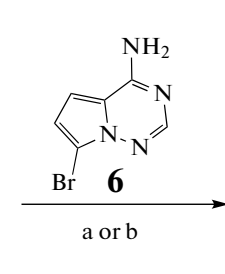

5<smiles>Nc1ncnn2c(C3(O)O[C@H](COCc4ccccc4)[C@@H](OCc4ccccc4)[C@H]3O)ccc12</smiles>

Mixture of isomers

a: $n$-BuLi, TMSCl, $-78^{\circ} \mathrm{C}, 25 \%$, b: 1,2-bis(chlorodimethylsilyl)ethane, NaH, $n$-BuLi, THF, $-78^{\circ} \mathrm{C}, 60 \%$

Scheme 1. Synthesis of compound 1 (GS441524).

The next step was reaction of ribolactone 5 with a bromo pyrrolotriazine nucleus $\mathbf{6}$. Two conditions were examined to achieve the $\mathrm{C}-\mathrm{C}$ bond formation affording compound 7. The first method (i.e.: a) involves addition of compound 6 to excess $n$ - BuLi at $-78^{\circ} \mathrm{C}$

$$
\begin{aligned}
& \frac{-1}{1} \\
& 3
\end{aligned}
$$

Fig. 5. Structure of compound $\mathbf{3}$ as metabolite of remdesivir. which results in lithium-halogen exchange facilitating by $N$-silyl protection of compound $\mathbf{6}$. Then, addition of this in situ generated reagent to the ribolactone 5 affords intermediate 7 in $25 \%$ yield [27, 33]. The another condition (i.e.: b) employs 1,2-bis(chlorodimethylsilyl) ethane and sodium hydride, followed by lithium-halogen exchange, and addition to the lactone 5 to generate 7 in $60 \%$ yield $[19,33]$. Compound 7 was separated as a mixture of two 1'-isomers which undergoes the subsequent 1 -cyanation reaction to obtain the $\beta$-anomer 8 after purification by chromatography [34]. Subsequently, three benzyl groups deprotection affords the 1'-cyano modified adenine nucleoside 1.

As can be seen in Scheme 2, the diastereomeric mixture of the phosphoramidoyl chloridate prodrug 11 was prepared from the L-alanine analogue 9 [35]. 


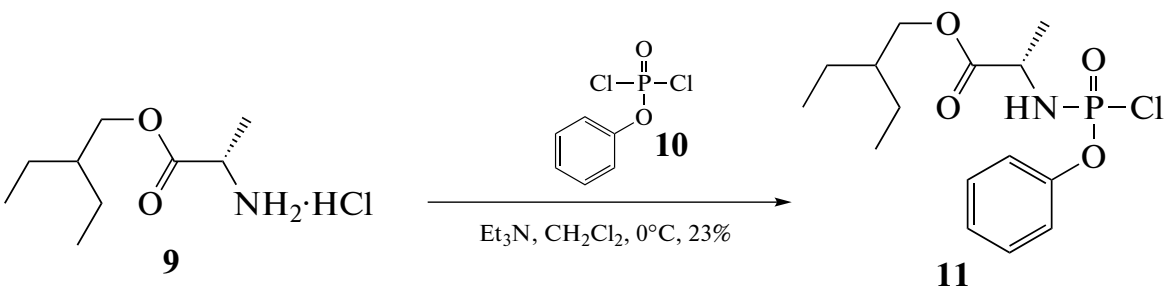

Diastereoisomeric mixture

Scheme 2. Preparation of diastereoisomeric mixture of compound 11.

Finally, coupling of nucleoside 1 with chloridate 11 affords the phosphoramidate prodrug mixture 2 almost in $1: 1$ diastereomeric ratio. Using chiral HPLC, the two diastereomers were separated to provide the $\mathrm{Sp} \mathbf{2 a}$ and $\mathrm{Rp} \mathbf{2 b}$ isomers, respectively (Scheme 3) [12]. However, the differences in yields, suboptimal selectivity, dependency on rate of $n$-BuLi addition, frequent use of cryogenic temperatures, and need for chiral chromatography restrict the application of this method in a large scale synthesis. In continue, Mackman and coworkers efforts were directed towards using milder reagents and temperature and obtaining enhanced selectivity (Scheme 4) $[8,27]$.<smiles>[R16][R16][Na]</smiles>

Scheme 3. Gilead Sciences, Inc synthesis method for preparation of Sp (remdesivir) and Rp isomer. 
<smiles>Nc1ncnn2c(C3(O)O[C@H](COCc4ccccc4)[C@@H](Br)[C@H]3OCc3ccccc3)ccc12</smiles><smiles>N#C[C@]1(c2ccc3c(N)ncnn23)O[C@](C#N)(c2ccc3c(N)ncnn23)[C@H](O)[C@@H]1COCc1ccccc1</smiles>
$>95: 5$ anomeric ratio

8

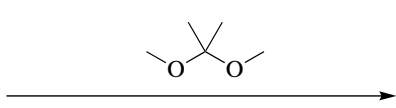

$\mathrm{H}_{2} \mathrm{SO}_{4}$, acetone, $\mathrm{rt}, 90 \%$<smiles>CC1(C)O[C@@H]2[C@H](O1)[C@@](C#N)(c1ccc3c(N)ncnn13)O[C@@H]2CO</smiles>

13

Scheme 4. Synthesis of compound 13.

The second preparative method [8, 27] was reported with preparation of the single $\mathrm{Sp}$ isomer (remdesivir) on suitable scales. According to Scheme 4, the glycosylation step employed the iodo-base $\mathbf{1 2}$ instead of the bromo-base $\mathbf{6}$ with replacement of the inconsistent $n$-BuLi method by the Turbo Grignard reagent $i-\mathrm{PrMgCl} . \mathrm{LiCl}$ [36]. Treatment of $\mathrm{PhMgCl}$ with TMSCl has led to a better control in the amino protection, and the use of iodo-base $\mathbf{1 2}$ has enabled more facile metal-halogen exchange than its bromo derivative. Then, addition of $i$ - $\mathrm{PrMgCl}$. $\mathrm{LiCl}$ followed by the ribolactone 5 at $-20^{\circ} \mathrm{C}$ produced the glycosylated intermediate 7 in $40 \%$ yield. This current protocol was more accepted due to its consistent yields at milder temperatures, hence it is more proper for scaleup synthesis.
The reaction of 7 with TMSCN, TMSOTf, and $\mathrm{TfOH}$ at $-78^{\circ} \mathrm{C}$ gave the product 8 nearly in $95: 5$ anomeric ratio. The presence of $\mathrm{TfOH}$ was crucial for acquiring the high yield and selectivity toward the desired $\beta$-anomer. Removal of three benzyl protecting groups was carried out through the reaction of $\mathbf{8}$ with $\mathrm{BCl}_{3}$ to afford compound 1 after crystallization. To prepare compound $\mathbf{1 3}$ in a high yield, 2',3'-acetonide protection of the hydroxyl moieties was conducted using 2,2-dimethoxypropane in the presence of $\mathrm{H}_{2} \mathrm{SO}_{4}[27,37]$.

As can be seen in Scheme 5, choosing $p$-nitrophenolate precursor 14 instead of chloridate 11 generates a single $\mathrm{Sp}$ isomer $\mathbf{1 5}$ after crystallization. This route is very effective towards the stereoselective synthesis of the final product [27].<smiles></smiles>

$\mathrm{Et}_{3} \mathrm{~N}, \mathrm{CH}_{2} \mathrm{Cl}_{2},-78^{\circ} \mathrm{C}, 80 \%$

Single Sp isomer

Scheme 5. Pathway for preparation of $\mathrm{Sp}$ isomer. 
The reaction of the acetonide protected nucleoside 13 with compound 15 in the presence of $\mathrm{MgCl}_{2}$ and Hunig's base affords the corresponding intermediate in $70 \%$ yield as a single $\mathrm{Sp}$ isomer through
$\mathrm{S}_{\mathrm{N}^{2}}$ type inversion of the phosphorus stereocenter. Finally, the deprotection of the acetonide with concentrated $\mathrm{HCl}$ in THF afforded 2 in $69 \%$ yield (Scheme 6) [27, 37].

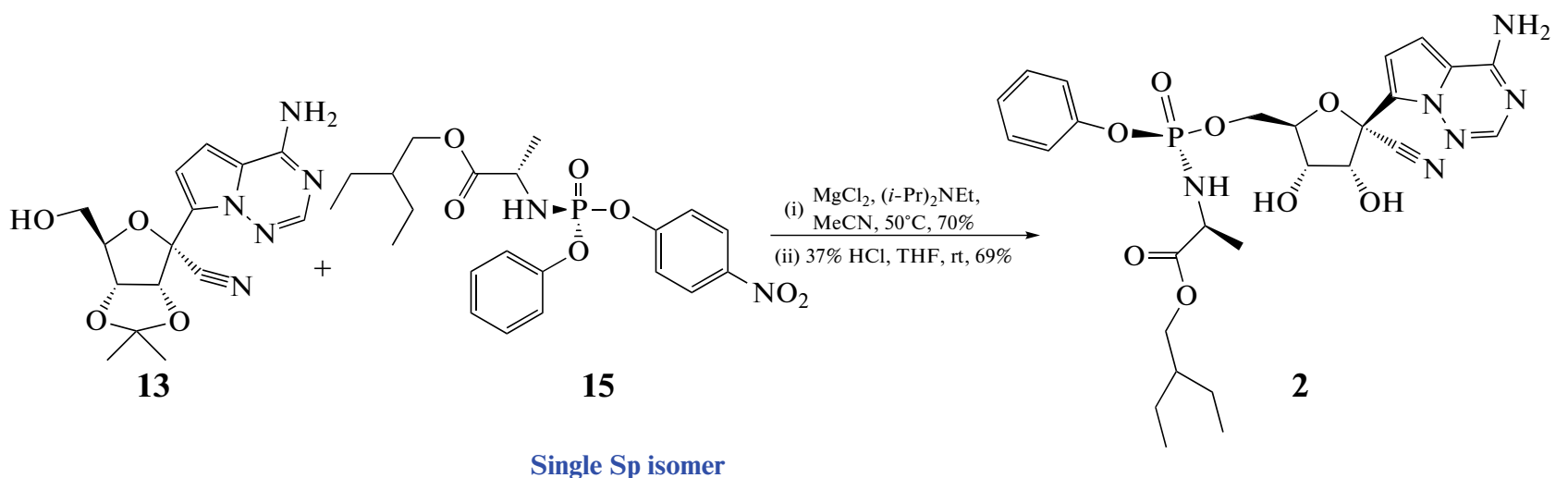

Scheme 6. The effective method for synthesis of compound 2

In this paper, the second preparative method for synthesis of remdesivir was reported with remarkable improvements in terms of yields, stereoselectivity and scalability by chiral separation [27].

In 2012, scientist at Gilead company synthesized a series of 1'-substituted 4-aza-7,9-dideazaadenosine $\mathrm{C}$-nucleosides [19]. This group of nucleosides displayed a wide range of inhibitory activity against several RNA viruses. This approach was started with lithiating a bromo pyrrolotriazine nucleus 6 (Scheme 7) [38]. Since compound 6 has an amino group with acidic property and its low solubility in $\mathrm{THF}$, the excess of $n$ - $\mathrm{BuLi}$ at $-78^{\circ} \mathrm{C}$ provided the lithio compound which is reacted with the tribenzyl lactone 5 [39] to afford 7 with anomeric ratio of 3 : 1 in $38 \%$ yield. The researchers have found that the yield of compound 7 can be increased to $60 \%$ when the 6 -amino group of $\mathbf{6}$ was transiently protected as its stable adduct $[34,40,41]$. The hemiacetal 7 was then subjected to anomeric reduction using Trimethylsilyl cyanide (TMSCN) and boron trifluoride etherate to obtain compound $\mathbf{8}$. The reaction was carried out at $0^{\circ} \mathrm{C}$ to yield of $85: 15$ for $\beta: \alpha$ anomers ratio, respectively. Removal of the three benzyl protecting groups was carried out using boron trichloride to afford the corresponding nucleoside 1 within three steps (Scheme 7).

In another study, Metobo and coworkers reported the synthesis of 1-substituted tubercidin C-nucleoside analogues (Scheme 8) [34]. The synthesis was started with lithiation of compound 6 [38] which is soluble in THF. The addition of $n$-butyl lithium to 6 at $-78^{\circ} \mathrm{C}$ produces the lithio compound which reacts with lactone 5 [39] to obtain hemiacetal 7. In this procedure, the absolute stereochemistry was not determined. The resulting hemiacetal 7 was then subjected to anomeric reduction using triethylsilane and boron trifluoride etherate to provide $8 \mathrm{~d}$. The reaction was carried out at $0^{\circ} \mathrm{C}$ to yield $95: 5$ ratio of $\beta: \alpha$ anomers. Subsequently, the benzyl protecting groups were removed using boron trichloride to afford compound $1 \mathrm{~d}$ in $40 \%$ yield.

This research group also reported that compound 7 could act as an intermediate for preparation of 1'-substituted nucleoside derivatives [34] (Scheme 9). 


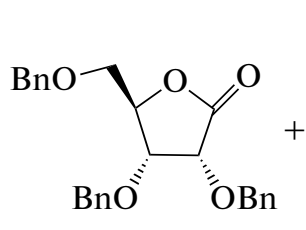

5

1,1,4,4-Tetramethyl-1,4-dichlorodisilylethylene $\mathrm{NaH}, n-\mathrm{BuLi}, \mathrm{THF}$, $-78^{\circ} \mathrm{C}, 1 \mathrm{~h}, 60 \%$<smiles>Nc1ncnn2c(C3(O)OC(COCc4ccccc4)[C@@H](Br)[C@H]3O)ccc12</smiles>
$\mathrm{Br}$<smiles>Nc1ncnn2c(Br)ccc12</smiles>

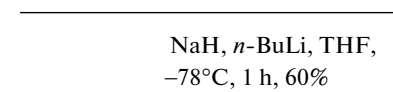
$\mathrm{BnO}$ " $\mathrm{OBn}$ Mixture of isomers

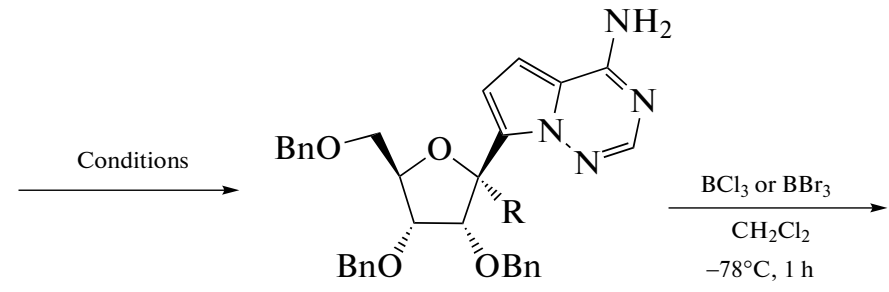

8

$8 a$

$8 b$

Condition

$8 c$

8: $\mathrm{TMSCN}, \mathrm{BF}_{3} \cdot \mathrm{OEt}_{2}, \mathrm{CH}_{2} \mathrm{Cl}_{2},-78^{\circ} \mathrm{C}, 5 \mathrm{~h}, 58 \%(85: 15 \beta: \alpha)$

8a: $\mathrm{AlMe}_{3}, \mathrm{BF}_{3} \cdot \mathrm{OEt}_{2}, \mathrm{CH}_{2} \mathrm{Cl}_{2}, 0^{\circ} \mathrm{C}, 12 \mathrm{~h}, 45 \%(1: 1 \beta: \alpha)$

8b: $\mathrm{CH}_{2}=\mathrm{CHMgBr}, \mathrm{THF}, 0^{\circ} \mathrm{C}$ to rt, $2 \mathrm{~h}$, and then $\mathrm{MsOH}$ (cat.), $\mathrm{CH}_{2} \mathrm{Cl}_{2}, \mathrm{rt}, 3 \mathrm{~h}, 85 \%(1: 1 \beta: \alpha)$

8c: $\mathrm{HC} \equiv \mathrm{C}-\mathrm{MgCl}$, THF, $0^{\circ} \mathrm{C}$ to rt, $2 \mathrm{~h}$, and then $\mathrm{MsOH}$ (cat.), $\mathrm{CH}_{2} \mathrm{Cl}_{2}, \mathrm{rt}, 3 \mathrm{~h}, 65 \%(2: 1 \beta: \alpha)$

Scheme 7. The pathway for synthesis of compound $\mathbf{1}$ and their derivatives

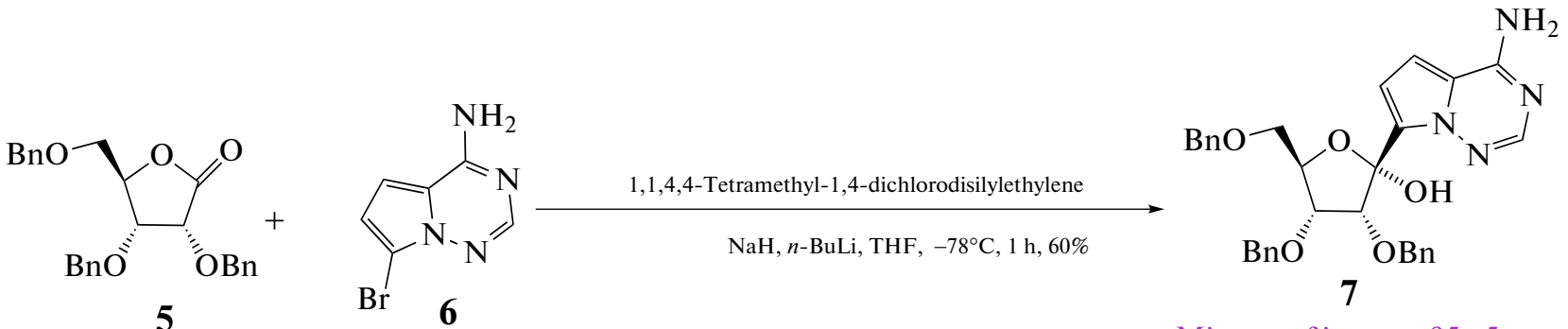

5<smiles>Nc1ncnn2c([C@H]3O[C@H](COc4ccccc4)[C@@H](OCc4ccccc4)[C@H]3O)ccc12</smiles>

8d

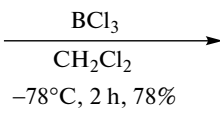

$-78^{\circ} \mathrm{C}, 2 \mathrm{~h}, 78 \%$
$82 \%$

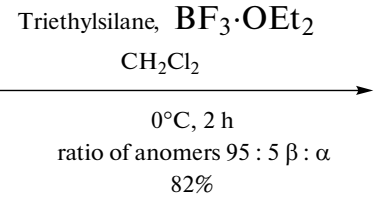
$1 \mathrm{R}=\mathrm{CN}$
1a $\mathrm{R}=\mathrm{CH}_{3}$
1b $\mathrm{R}=$ Vinyl
1c $\mathrm{R}=$ Ethynyl

Mixture of isomers $95: 5$

Scheme 8. Synthesis method for preparation of 1d. 


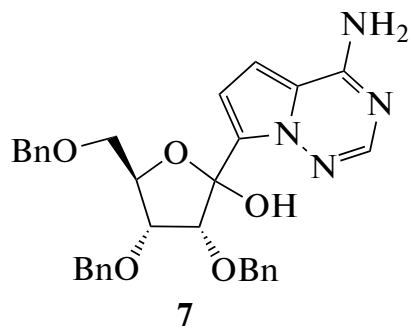

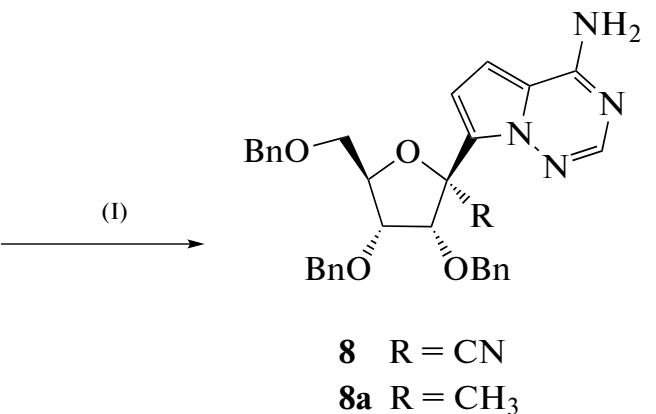

Reagents and conditions (I):

8: TMSCN, TMSOTf, $\mathrm{CH}_{2} \mathrm{Cl}_{2}, 0^{\circ} \mathrm{C}$, ratio of anomers $57: 43(\beta: \alpha), 76 \%,-78^{\circ} \mathrm{C}, 5 \mathrm{~h}, 65 \%, 89: 11(\beta: \alpha)$

TMSCN, $\mathrm{BF}_{3} \cdot \mathrm{OEt}_{2}, \mathrm{CH}_{2} \mathrm{Cl}_{2},-78^{\circ} \mathrm{C}, 5 \mathrm{~h}, 58 \%, 85: 15(\beta: \alpha)$.

8a: $\mathrm{AlMe}_{3}, \mathrm{BF}_{3} \cdot \mathrm{OEt}_{2}, \mathrm{CH}_{2} \mathrm{Cl}_{2}, 0^{\circ} \mathrm{C}, 12 \mathrm{~h}, 45 \% 52: 48(\beta: \alpha)$.

Scheme 9. The pat way for synthesis of compound $\mathbf{8}$ and $\mathbf{8 a}$.

The stereochemical alterations through the addition of diverse nucleophiles to 7 was also investigated. Nitrile 8 was obtained using trimethylsilyl cyanide in the presence of boron trifluoride etherate. Unlike the obtained results from the anomeric reductions with trimethylsilyl cyanide at $0^{\circ} \mathrm{C}$ with no stereoselectivity $(57: 43 \beta: \alpha)$, when the reaction was carried out at $-78^{\circ} \mathrm{C}$, the anomeric stereoselectivity was enhanced to $89: 11(\beta: \alpha)$ in $65 \%$ yield. It is clear that temperature influenced on the sterioisomeric ratio. Nitrile 8 was also prepared in the presence of boron trifluoride diethyl etherate as a Lewis acid without any significant diminishment in selectivity and yield $(85: 15, \beta: \alpha)$. To prepare 1'-methyl analogue 8a, the reaction was performed at $0^{\circ} \mathrm{C}$ in the presence of trimethyl aluminum and boron trifluoride etherate to afford approximately $45 \%$ yield of product in $52: 48(\beta: \alpha)$ mixture of the two anomers [34].

Metobo and coworkers reported that temperature has remarkably affected the stereoisomeric ratio when compound $\mathbf{7}$ is encountered the certain nucleophiles [34]. The suggested mechanism for the stereoselective anomeric reduction of 7 is shown in Scheme 10 [34].

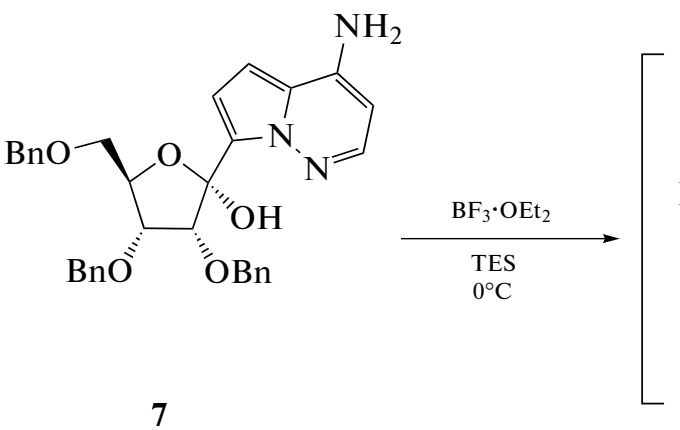

7

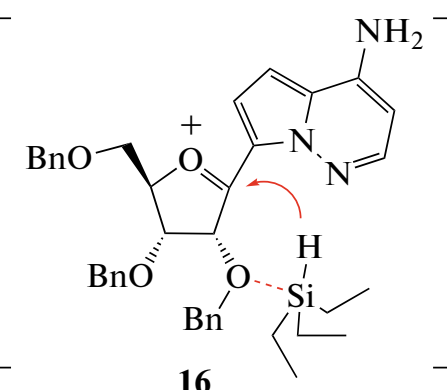

16

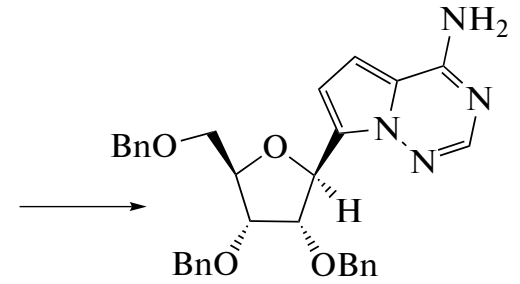

8d

Scheme 10. Proposed mechanism for stereoselective dehydroxylation of 7.

The interaction of silicon at $0^{\circ} \mathrm{C}$ with oxygen of benzyloxy moiety at $\mathrm{C}\left(2^{\prime}\right)$ in compound 7 results in hydride attack at $\mathrm{C}\left(1^{\prime}\right)$ in favored face to furnish only the $\beta$ anomer. For $8 d$, this proposed chelation is compromised as evidenced by the loss of its selectivity. However, at $-78^{\circ} \mathrm{C}$, the stereoselectivity in the cyanation step is occurred and chelation of the silicon atom of the trimethylsilyl cyanide with the benzyloxy group is achieved, effectively (Fig. 6). This interaction leads to the suitable attack of the cyanide from the favorable face.
To date, it is not clear that either 2' or 3' benzyloxy group plays an important role to determine the streoselectivity. The result of methyl addition to the 1' position has indicated that $1: 1(\beta: \alpha)$ anomeric mixture of the corresponding product is obtained that attributed to weaker interaction between aluminum and benzyloxy group at $0^{\circ} \mathrm{C}$ [34].

Vieira and coworkers reported the novel method for development of a manufacturing scale for cyanation process using continuous flow chemistry en route to synthesize remdesivier [42]. To scale-up synthesis 
of compound 8, two procedures were developed: $(i)$ a batch cyanation process for preparation of compound 8; (ii) using continuous flow for a cyanation process. The first method requires cryogenic reaction temperatures; however, Vieira and coworkers optimized the reaction conditions and reported a larger-scale synthesis of remdesivir. Throughout the scale-up synthesis, trimethylsilyl trifluoromethanesulfonate (TMSOTf) and trimethylsilyl cyanide (TMSCN) were each added over roughly $30 \mathrm{~min}$ to continue the reac- tion at the target temperature of $-30^{\circ} \mathrm{C}$ (Scheme 11). Increasing the time to $30 \mathrm{~min}$ leads to decomposition of the reaction mixture and lower diastereoselectivity. This result was achieved by combining the starting material 7 in dichloromethane (DCM) and trifluoroacetic acid (TFA) at $-30^{\circ} \mathrm{C}$ and adding a mixture of TMSOTf and TMSCN in DCM at $-30^{\circ} \mathrm{C}$. The compound 8 could be selectivity crystallized from either mixed solvent system (ethyl acetate and heptane) or single solvent such as 2-propanol or toluene.<smiles>Nc1ncnn2c(C3(O)O[C@H](COCc4ccccc4)[C@@H](Br)[C@H]3Br)ccc12</smiles>
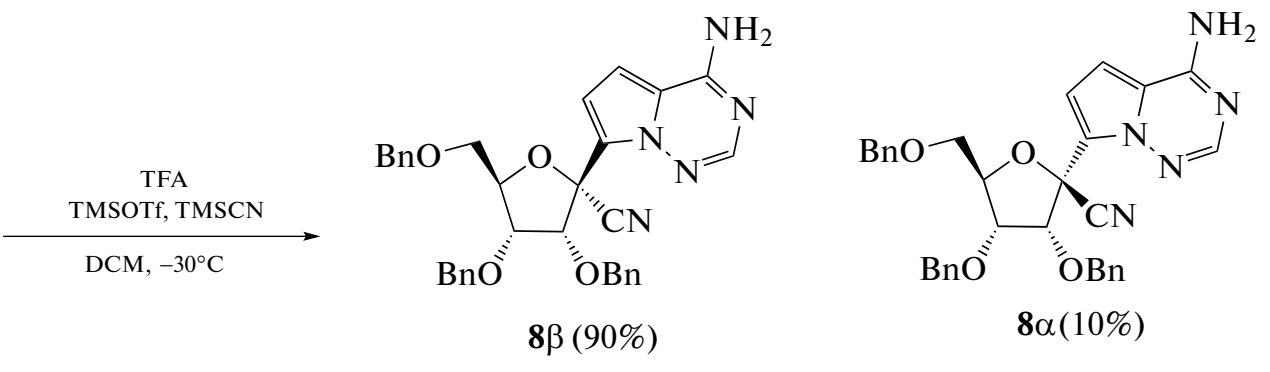

Scheme 11. The preparation method for synthesis of $8(\alpha(10 \%) \& \beta(90 \%))$.

As can be seen in Scheme 12, Vieira and coworkers has reported a new and effective method for preparation of large scale of compound 7 [42]. According to Scheme 12, anhydrous neodymium(III) chloride, tetra- $n$-butylammonium chloride and tetrahydrofuran were used and the mixture was cooled to $22^{\circ} \mathrm{C}$. Then, compound 5 was added and the mixture was cooled to $-20^{\circ} \mathrm{C}$. Next, in a double-necked round-bottom flask, compound $\mathbf{1 2}$ and THF was combined and cooled about $0^{\circ} \mathrm{C}$. Afterward, chlorotrimethylsilane was added slowly and after $30 \mathrm{~min}$, the mixture was cooled to $-10^{\circ} \mathrm{C}$. Phenylmagnesium chloride (in THF) was charged slowly and after $30 \mathrm{~min}$ the reaction mixture was cooled to $-20^{\circ} \mathrm{C}$. Isopropylmagnesium chloride was added dropwise and after $2 \mathrm{~h}$, the Gri-

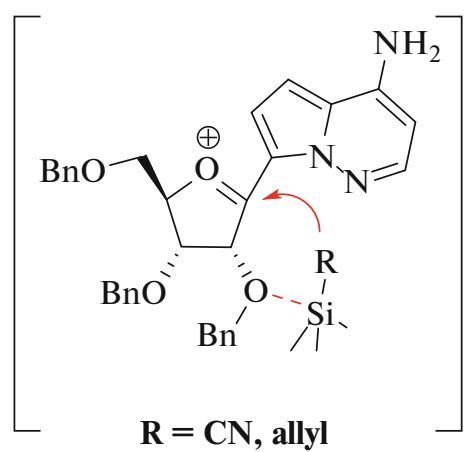

Fig. 6. Interaction of compound 7 with triethylsilyl reagent. gnard reaction mixture was transferred into the lactone $/ \mathrm{NdCl}_{3} / n-\mathrm{Bu}_{4} \mathrm{NCl} / \mathrm{THF}$ mixture. The resulting mixture was stirred at $-20^{\circ} \mathrm{C}$, and after $8 \mathrm{~h}$, a solution of acetic acid and water was added. The resulting mixture was warmed to $22^{\circ} \mathrm{C}$, and isopropyl acetate $(i$-PrOAc) was added. The organic layer was separated and washed with aqueous potassium bicarbonate and aqueous sodium chloride. Then, $i$-PrOAc was charged again and the mixture was washed with water. After evaporation of organic layer in vacuo, the methyl tertbutyl ether (MTBE) was charged, and the mixture was adjusted to about $22^{\circ} \mathrm{C}$, the crystals of compound $\mathbf{1}$ were prepared and the mixture was cooled to $0^{\circ} \mathrm{C}$. Then, compound 7 was dried in vacuo and the resulting yield was $69 \%$ with $100 \%$ purity.

Xue et al. was improved the C-glycosylation step for the synthesis of remdesivir [43]. As can be seen in Scheme 13, efficient protection of the free amine group in 6 would be essential for the successful addition reaction of base 6 to lactone 5. They confirmed that the addition of a secondary amine such as diisopropylamine can be useful for improving the reaction efficiency. The importance of this method is amenable to hectogram scale synthesis of product 7 without column chromatographic operations in large-scale manufacture and this procedure would be highly advantageous for the large-scale manufacture of the remdesivir [43]. 


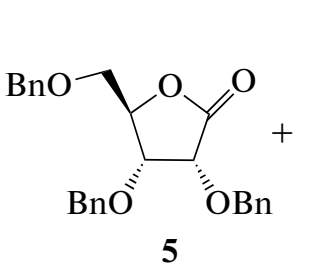<smiles>Nc1ncnn2c(I)ccc12</smiles>
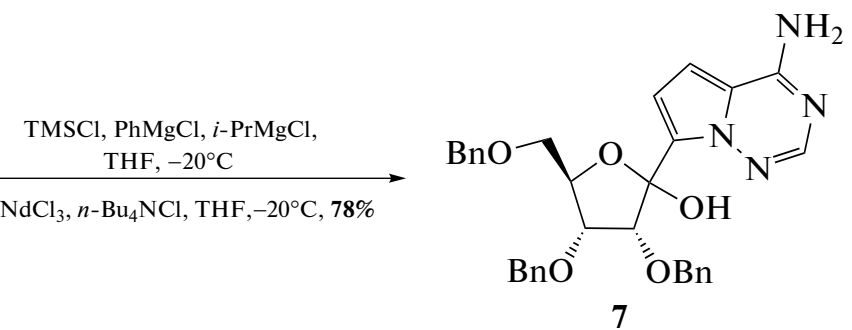

Scheme 12. The effective method for preparation of large scale of compound 7<smiles>Nc1ncnn2c(Br)ccc12</smiles>

6<smiles>[B]OC[C@H]1OC(=O)[C@H](Br)[C@@H]1Br</smiles>

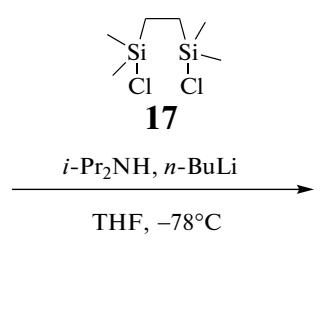<smiles>Nc1ncnn2c([C@]3(O)O[C@H](COCBr)[C@@H](OCc4ccccc4)[C@H]3OCc3ccccc3)ccc12</smiles>

10.0 g scale: $74 \%$ (chromatography)

180.0 g scale: $62 \%$ (recrystalization)

Reactions condition: 1.1 eq of $\mathbf{1 7}, 1.1$ eq of $i-\mathrm{Pr}_{2} \mathrm{NH}$, and 4.3 eq of $n-\mathrm{BuLi}$

Scheme 13. Scale-up synthesis of compound 7.

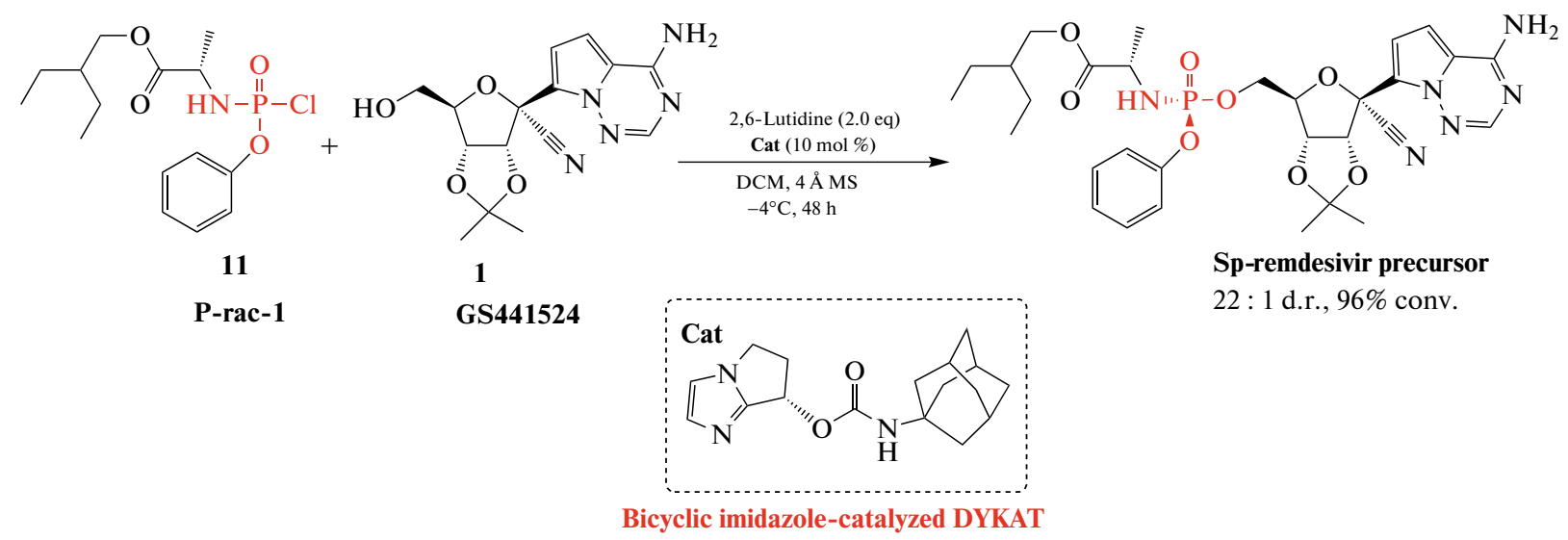

Scheme 14. Catalytic asymmetric synthesis of remdesivir.

Wang et al reported the novel and efficient method for developing the catalytic asymmetric synthesis of the remdesivir [44]. As can be seen in Scheme 14, they confirmed that the chiral bicyclic imidazole catalyzed the coupling of the $P$-racemic phosphoryl chloride $\mathbf{1 1}$ with protected nucleoside 1 (GS441524). This unique chiral catalyst was very important for the dynamic kinetic asymmetric transformation (DyKAT) to proceed excellent stereoselectivity (96\% conv., $22: 1 \mathrm{Sp}$ : $\mathrm{Rp})$. This group recognized 10 -gram scale reaction of compounds 11 and $\mathbf{1}$ in the present of $10 \mathrm{~mol} \%$ of effective chiral bicyclic imidazole catalyst and 2,6lutidine as a base in DCM at $-40^{\circ} \mathrm{C}$ for 48 hours produced Sp-remdesivir with $96 \%$ conversion (22: $1 \mathrm{Sp}$ : $\mathrm{Rp})$. In conclusion, this method of synthesis showed its potential for industrial application and mass production [44].

Owing to pandemic of COVID-19 in the whole world, thus it is critically essential to develop therapies for COVID-19 [45]. Recently, remdesivir as a promising drug for COVID-19 has received more attention, this drug has played an important role in mitigating the mortality and morbidity [46-53], therefore the potential therapeutic properties of this drug have encouraged the organic and medicinal chemists and other researchers to find the new synthetic procedures and methods [31, 37, 43, 54]. This review help organic and medicinal chemists to compare diverse methods for synthesis of remdesivir. 


\section{CONCLUSION}

Recently, WHO declared COVID-19 pandemic as a public health emergency of international concern (PHEIC). Since then, researchers across the world have motivated to discover, develop and evaluate potential therapeutics against SARS-CoV-2. Evaluating an effective small chemical molecule drug will be the best, fast and effective therapeutic method. Between various antiviral candidate therapies, remdesivir has demonstrated to be a potent antiviral drug that inhibits viral RNA synthesis. Recently, there are supportive evidences for yielding some clinical improvement in COVID-19 patients. Based on these findings, FDA and EMA have issued an emergency use authorization for the emergency use of remdesivir as the treatment of hospitalized COVID-19 patients. This is the first drug that having FDA and EMA approval for marketing as a treatment for SARS-CoV-2. As a result, synthesis of this effective antiviral drug has attracted considerable attention across the world. Herein, we briefly discussed about discovery and synthesis of remdesivir.

\section{FUNDING}

The authors wish to thank the support of Noncommunicable Diseases Research Center, School of Medicine, Fasa University of Medical Sciences (Grant no. 99085) and Shiraz University of Technology. Also, this research has been ethically approved, IR.FUMS.REC.1399.092.

\section{COMPLIANCE WITH ETHICAL STANDARDS}

This article does not contain any studies involving human participants performed by any of the authors and does not contain any studies involving animals performed by any of the authors.

\section{Conflict of Interests}

There is no conflict of interest.

\section{REFERENCES}

1. Loeffelholz, M.J. and Tang, Y.-W., Emerg. Microb. Infect., 2020, vol. 9, no. 1, pp. 747-756.

2. Kim, D., Lee, J.-Y., Yang, J.-S., Kim, J.W., Kim, V.N., and Chang, H., Cell, 2020, vol. 181, pp. 914-921.e10.

3. Andersen, K.G., Rambaut, A., Lipkin, W.I., Holmes, E.C., and Garry, R.F., Nat. Med., 2020, vol. 26, no. 4, pp. $450-452$.

4. Geller, C., Varbanov, M., and Duval, R.E., Viruses, 2012, vol. 4, no. 11, pp. 3044-3068.

5. Song, Z., Xu, Y., Bao, L., Zhang, L., Yu, P., Qu, Y., Zhu, H., Zhao, W., Han, Y., and Qin, C., Viruses, 2019, vol. 11, no. 1, p. 59.
6. WHO Infection Prevention and Control Global Newsletter. https://mailchi.mp/f1c7b3f75630/ipc-globalnewsletter-march-2020? $\mathrm{e}=\mathrm{c} 4 \mathrm{~d} 8147 \mathrm{ad} 8$.

7. Tu, Y.-F., Chien, C.-S., Yarmishyn, A. A., Lin, Y.-Y., Luo, Y.-H., Lin, Y.-T., Lai, W.-Y., Yang, D.-M., Chou, S.-J., and Yang, Y.-P., Int. J. Mol. Sci., 2020, vol. 21, no. 7, p. 2657.

8. Warren, T., Jordan, R., Lo, M., Soloveva, V., Ray, A., Bannister, R., Mackman, R., Perron, M., Stray, K., and Feng, J., Open Forum Infectious Diseases, 2015.

9. Balasubramanian, M., Covid 19-The New Age Pandemic, Notion Press, 2020.

10. Ison, M. G., Wolfe, C., and Boucher, H. W., JAMA, 2020, vol. 323, pp. 2365-2366.

11. Levene, P. and Jacobs, W., Berichte der deutschen chemischen Gesellschaft, 1909, vol. 42, no. 1, pp. 11981203.

12. Axt, S. D. B., P. R., Brak, K., Campagna, S., Chtchemelinine, A., Chun, B. K., Clarke, M. O. H., Doerffler, E., Frick, M. M., Gao, D., Heumann, L. V., Hoang, B., Hui, and H. C., Jordan R., Lew, W. M., R. L., Milburn, R. R., Neville, S. T., Parrish, J. P., Ray, A. S., Ross, B., Rueden, E., Scott, R. W., Siegel, D., Stevens, A. C., Tadeus, C., Vieira, T., Waltman, A. W., Wang, X., Whitcomb, M. C., Wolfe, L., and Yu, C.-Y., U.S. Patent no. 2015017934, 2015.

13. Yates, M. K. and Seley-Radtke, K. L., Antiviral Res., 2019, vol. 162, pp. 5-21.

14. Soltani Rad, M.N., Behrouz, S., Zarenezhad, E., and Kaviani, N., J. Iran. Chem. Soc., 2015, vol. 12, no. 9, pp. 1603-1612.

15. Behrouz, S., Soltani Rad, M.N., and Piltan, M.A., Chem. Papers, 2020, vol. 74, no. 1, pp. 113-124.

16. Zarenezhad, E., Mosslemin, M. H., Alborzi, A., Anaraki-Ardakani, H., Shams, N., Khoshnood, M.M., and Zarenezhad, A., J. Chem. Res., 2014, vol. 38, no. 6, pp. 337-340.

17. Ichikawa, E. and Kato, K., Curr. Med. Chem., 2001, vol. 8, no. 4, pp. 385-423.

18. Cappellacci, L., Barboni, G., Palmieri, M., Pasqualini, M., Grifantini, M., Costa, B., Martini, C., and Franchetti, P., J. Med. Chem., 2002, vol. 45, no. 6, pp. 1196-1202.

19. Cho, A., Saunders, O. L., Butler, T., Zhang, L., Xu, J., Vela, J.E., Feng, J.Y., Ray, A.S., and Kim, C.U., Bioorg. Med. Chem. Lett., 2012, vol. 22, no. 8, pp. 27052707.

20. Temburnikar, K. and Seley-Radtke, K.L., Beilstein J. Org. Chem., 2018, vol. 14, no. 1, pp. 772-785.

21. Rios, A.C., Yu, H.T. and Tor,Y., J. Phys. Org. Chem., 2015, vol. 28, no. 3, pp. 173-180.

22. Levy, M. and Miller, S.L., Proc. Natl. Acad. Sci. U. S. A., 1998, vol. 95, no. 14, pp. 7933-7938.

23. Berti, P.J. and McCann, J.A., Chem. Rev., 2006, vol. 106, no. 2, pp. 506-555.

24. Lenz, S.A., Kohout, J.D., and Wetmore, S.D., J. Phys. Chem. B, 2016, vol. 120, no. 50, pp. 12795-12806.

25. De Clercq, E., J. Med. Chem., 2016, vol. 59, no. 6, pp. 2301-2311.

26. Hocek, M., Chem. Rev., 2009, vol. 109, no. 12, pp. 6729-6764. 
27. Siegel, D., Hui, H.C., Doerffler, E., Clarke, M. O., Chun, K., Zhang, L., Neville, S., Carra, E., Lew, W., and Ross, B., ACS Publications, 2017.

28. Warren, T.K., Jordan, R., Lo, M.K., Ray, A.S., Mackman, R.L., Soloveva, V., Siegel, D., Perron, M., Bannister, R., and Hui, H.C., et al., Nature, 2016, vol. 531, pp. 381-385.

29. Mehellou, Y., Balzarini, J., and McGuigan, C., ChemMedChem: Chemistry Enabling Drug Discovery, 2009, vol. 4, no. 11, pp. 1779-1791.

30. Seley-Radtke, K. L. and Yates, M. K., Antiviral Res., 2018, vol. 154, pp. 66-86.

31. Liang, C., Tian, L., Liu, Y., Hui, N., Qiao, G., Li, H., Shi, Z., Tang, Y., Zhang, D., and Xie, X., Eur. J. Med. Chem., 2020, p. 112527.

32. Eastman, R.T., Roth, J.S., Brimacombe, K.R., Simeonov, A., Shen, M., Patnaik, S., and Hall, M.D., $A C S$ Centr. Sci., 2020, vol. 6, pp. 672-683.

33. Butler, T., Cho, A., Graetz, B.R., Kim, C.U., Metobo, S.E., Saunders, O.L., Waltman, A. W., Xu, J., and Zhang, L., Google Patents, 2018.

34. Metobo, S. ., Xu, J., Saunders, O.L., Butler, T., Aktoudianakis, E., Cho, A., and Kim, C.U., Tetrahedron Lett., 2012, vol. 53, no. 5, pp. 484-486.

35. Mackman, R.L., Parrish, J.P., Ray, A.S., and Theodore, D.A., US Patent no. 2011045102, 2011.

36. Krasovskiy, A. and Knochel, P., Angew. Chem. Int. Ed., 2004, vol. 43, no. 25, pp. 3333-3336.

37. Wang, Z. and Yang, L., New J. Chem., 2020, vol. 44, no. 29, pp. 12417-12429.

38. Bayer, US4608, 2006.

39. Alessandrini, L., Casati, S., Ciuffreda, P., Ottria, R., and Santaniello, E., J. Carbohydr. Chem., 2008, vol. 27, no. 5, pp. 332-344.

40. Djuric, S., Venit, J., and Magnus, P., Tetrahedron Lett., 1981, vol. 22, no. 19, pp. 1787-1790.
41. Hildbrand, S., Blaser, A., Parel, S.P., and Leumann, C.J., J. Am. Chem. Soc., 1997, vol. 119, no. 24, pp. 54995511.

42. Vieira, T., Stevens, A., Chtchemelinine, A., Gao, D., Badalov, P., and Heumann, L., Org. Process Res. Dev., 2020, vol. 24, pp. 2113-2121.

43. Xue, F., Zhou, X., Zhou, R., Zhou, X., Xiao, D., Gu, E., Guo, X., Xiang, J., Wang, K., and Yang, L., Org. Process Res. Dev., 2020, vol. 24, no. 9, pp. 1772-1777.

44. Wang, M., Zhang, L., Huo, X., Zhang, Z., Yuan, Q., Li, P., Chen, J., Zou, Y., Wu, Z., and Zhang, W., Angew. Chem. Int. Ed., 2020, vol. 59, no. 47, pp. 2081420819.

45. Sun, D., AAPS J., 2020, vol. 22, no. 4, p. 77.

46. Hashemian, S.M., Farhadi, T., and Velayati, A.A., Drug Des., Dev. Ther., 2020, vol. 14, pp. 3215.

47. Malin, J.J., Suárez, I., Priesner, V., Fätkenheuer, G. and Rybniker, J., Clin. Microbiol. Rev., 2020, vol. 34, no. 1, p. e00162-20.

48. Roshanshad, A., Kamalipour, A., Ashraf, M. A., Roshanshad, R., Jafari, S., Nazemi, P., and Akbari, M., Iran. J. Microbiol., 2020, vol. 12, no. 5, pp. 376-387.

49. Maciorowski, D., Idrissi, S.Z.E., Gupta, Y., Medernach, B.J., Burns, M.B., Becker, D.P., Durvasula, R., and Kempaiah, P., SLAS Discovery, 2020, vol. 25, no. 10 , pp. $1108-1122$.

50. Beigel, J., Tomashek, K., Dodd, L., et al. N. Engl. J. Med., 2020, vol. 383, pp. 1813-1826.

51. Frediansyah, A., Nainu, F., Dhama, K., Mudatsir, M., and Harapan, H., Clin. Epidemiol. Global Health, 2020, vol. 9, pp. 123-127.

52. Mehta, M. and Shyh, G. I., Cardiol. Rev., 2020, vol. 28, no. 6, pp. 332-334.

53. Neldi, V. and Suharjono, S., Pharm. Sci. Res., 2020, vol. 7, no. 4, p. 5.

54. Al Bujuq, N., Synthesis, 2020, vol. 52, no. 24, pp. 37353750 . 